\title{
On the Extension of the Model of Matrix Acid Stimulation to Different Sandstones
}

A model was developed for the acidization of various sandstone cores H. S. FOGLER which successfully describes the flow and reaction in the porous media during acidization. A comparison of the experimental results of various investigators shows excellent agreement with the results predicted by the authors with the model.

\section{SCOPE}

Acidization is the process of the injection of hydrofluoric and hydrochloric acid mixtures into oil and gas reservoirs to dissolve the rock and thereby increase the permeability and productivity of the well. Preinjection studies are often carried out on sandstone cores in a permeameter in an attempt to determine the amount and in what proportions the acid is to be injected into the reservoir. While previous work on sandstone cores has provided useful qualitative and quantitative descriptions of acidization for the particular type of sandstone studied, it has not provided a model which has general applicability to different types of sandstones. Recently, an intensive experimental investigation was undertaken on one particular sandstone, Phacoides sandstone. The development of a model for the acidization has made it possible to predict the movement of the permeability and acid fronts through the sandstone core. In addition, one can predict the overall permeability of Phacoides cores as a function of acid injection time. However, sandstone formations vary widely in composition, and for the model to have general validity, it must be applicable to sandstones other than Phacoides. This paper details how the model can be extended to various other sandstones to predict the movement of the permeability and acid fronts during acidization. Comparisons are made with the theoretical calculations from the model and the experimental results published by other investigators in the field.

\section{CONCLUSIONS AND SIGNIFICANCE}

The general applicability of a model to describe the acidization of different sandstone cores has been demonstrated. The three dimensionless parameters in the model which characterize the flow and reaction in porous media during acid stimulation are the Damkohler number, the acid capacity number, and the characteristic constant in the porosity-permeability relationship. With Phacoides sandstone, a feldspar rich quartzite rock, used as a basis for the calculations, an analytic method has been developed to estimate the acid capacity and Damkohler numbers for different sandstones solely from a mineralogical analysis and a porosity measurement on that sandstone.
Experimental results obtained by other investigators and those obtained by the authors agree remarkably well with the theoretical predictions. The extension of the model to other sandstones will be of great use in the design of the matrix acid stimulation of oil reservoirs with mineralogical compositions and properties similar to the sandstones studied. Extension of the model cannot be readily made, however, to sandstones that have large carbonate contents, a greater percentage of dissolvable material than inert material, or excessive damage occurring during acidization.
This is the eighth in a series of papers on acidization that have discussed the kinetics of the reaction of hydrogen fluoride and hydrogen chloride acid mixtures with some of the more common minerals found in sandstones (Lund et al., 1973; Lund et al., 1975; Fogler et al., 1975), the experimental techniques and correlations for the acidization of linear cores (McCune and Fogler, 1973; Lund et al., 1976), and the development of a model that predicts the movement of the permeability and acid fronts through sandstone cores as well as predicting the overall permeability as a function of acid injection time (Lund and Fogler, 1976). This linear model has been extended to acid injection into radial geometries to predict the position of the permeability front in the reservoirs as a function of the injection conditions (McCune et al., 1975).

Correspondence concerning this paper should be addressed to $H$. S. Fogler. C. C. McCune is with Chevron Oil Field Research Company, La Habra, California 90631.
Previous work in this series concentrates solely on Phacoides sandstone, and feldspar rich quartzite that contains commercial oil saturations in a number of areas in the San Joaquin Valley of California. This paper demonstrates how the model may be extended to other sandstones to predict the movement and breakthrough time of the permeability front. In performing this extension, previously published data by other authors working in the area as well as recent data obtained on Berea sandstone at Chevron Oil Field Research Company will be used.

\section{FLOW AND REACTION IN LINEAR CORES}

Differential mole balances on the dissolvable rock minerals and clays (lumped as feldspars) and the hydrofluoric acid in a linear sandstone core lead to the following set of coupled, nonlinear, partial differential equations (Lund and Fogler, 1976): 


$$
\phi_{o} \frac{\partial C}{\partial t}+V \frac{\partial C}{\partial z}+k_{1} C \Delta W=0
$$

where the product $\left(k_{1} C \Delta W\right)$ represents the rate law for the reaction of hydrogen fluoride with the dissolvable minerals, gram moles per cubic centimeter per minute. A mole balance on the dissolvable minerals yields

$$
\nu\left(1-\phi_{0}\right) \frac{\partial W}{\partial t}=-k_{1} C \Delta W
$$

In writing the differential mole balances for the acid and for the rock, we have applied the quasi steady state assumption to the variation of porosity with time. This assumption is valid provided the increase in porosity is less than or the same magnitude as initial porosity.

Writing the above mole balances in dimensionless form, we can determine the characteristic groups which describe the acidization process.

The dimensionless form of acid balance [Equation (1)] is

$$
\frac{\partial \Psi}{\partial \theta}+\frac{\partial \Psi}{\partial \epsilon}+(D a) \eta \Psi=0
$$

while the dimensionless form of the balance on the dissolvable minerals, Equation (2), becomes

$$
\frac{\partial \eta}{\partial \theta}=-(D a)(A c) \eta \Psi
$$

where $D a$ is the Damkohler number, ratio of rate of reaction of hydrogen fluoride to the rate of convection of hydrogen fluoride through the porous media

$$
D a=\frac{k_{1} L \Delta W_{o}}{V}
$$

$A c$ is the acid capacity number, molar ratio of acid present in the pore space to the acid required to dissolve all the mineral accessible to reaction

$$
A c=\phi_{o} C_{o} /\left[\nu\left(1-\phi_{o}\right)\left(\Delta W_{o}\right)\right]
$$

The change in porosity is related to the change in dissolvable mineral concentration through the relation

$$
\Delta \phi \equiv \phi-\phi_{0}=(1-\eta) \Delta \phi_{m}
$$

where $\Delta \phi_{m}$ is the maximum change in porosity resulting when all the dissolvable minerals accessible to reaction have been consumed.

The local permeability $k$ of a sandstone undergoing acidization can be expressed as the following function of the change in porosity (McCune and Fogler, 1973; Lund, 1974):

$$
k / k_{o}=\exp \left(\beta \frac{\Delta \phi}{\Delta \phi_{m}}\right)
$$

Here $\beta$ is an experimentally determined parameter (for Phacoides sandstone the value of $\beta$ was found to be $7.5)$, and $k_{0}$ is the initial permeability of the core. The ratio of the overall permeability over the length of the core to the initial permeability is

$$
K / k_{o}=1 / \int_{0}^{1} \frac{d \epsilon}{\left(k / k_{o}\right)}
$$

where $K$ is the overall permeability of the core at time $\theta$. The solutions to the partial differential Equations (3) and (4), which are (Lund, 1974)

$\Psi=$

$$
\begin{aligned}
& \frac{1}{1+\exp [D a A c|(1+1 / A c) \epsilon-\theta|]-\exp [D a A} \cdot \frac{1}{(\epsilon-\theta)]} \\
& \eta=\frac{18)}{1+\exp [-D a A c|(1+1 / A c) \epsilon-\theta|]-\exp \left(-D a_{\epsilon}\right)}
\end{aligned}
$$

together with Equations (5) and (6) describe the change in acid concentration, mineral concentration, porosity, and permeability as a function of the axial position down the core and the acid injection time. From the combination of Equations (5) to (9) one can also determine the overall permeability as a function of acid injection time.

Closer examination of Equations (8) and 9) shows that for large Damkohler numbers, the changes in acid and mineral concentrations (and hence porosity and permeability) move as a front through the core. Tie position of the fluid front (that is, interface between the distilled water originally present in the core and the acid mixture) is given by

$$
\epsilon=\theta
$$

The position of the reaction front is given by tha equation

$$
\epsilon=\frac{A c}{(1+A c)} \theta
$$

When the reaction and permeability fronts approach the end of the core $(\epsilon=1)$, the overall permeability rises sharply. The time required for the permeability front to travel through the core is defined as the permeability breakthrough time $t_{b}$. The dimensionless form of the permeability breakthrough time $\theta_{b}$ is just the number of pore volumes of acid that must be injected in order for the permeability front to reach the end of the core. For $\epsilon=1$, Equation (11) is rearranged to give the following relationship between $\theta_{b}$ and the acid capacity number:

$$
\theta_{b}=\frac{t_{b}}{\tau}=\frac{(1+A c)}{A c}
$$

The dimensional form of the permeability breakthrough time $t_{b}$ is obtained from Equation (12) as

$$
t_{b}=\frac{\phi_{0} L}{V}\left(\frac{1+A c}{A c}\right)
$$

In order to calculate the number of pore volumes that must be injected to reach the permeability breakthrough for a particular sandstone, one must determine the acid capacity number for that sandstone.

\section{PREDICTION OF THE DAMKOHLER AND ACID CAPACITY NUMBERS}

\section{Acid Capacity Number}

The acid capacity is a dimensionless number which characterizes the acidization process and is at measure of how fast the reaction front moves through the core. It is given by the equation (Lund and Fogler, 1976)

$$
A c=\frac{\phi_{0} C_{0}}{\nu\left(1-\phi_{0}\right)\left(\Delta W_{o}\right)}
$$

Rearranging Equation (14) into the following form

$$
\left|\frac{A c \nu}{C_{0}}\right|=\left|\frac{\phi_{0}}{\left(1-\phi_{0}\right)}\right|\left|\frac{1}{\Delta W_{0}}\right|
$$

we get a grouping of parameters (that is, $\phi_{0}$ and $\Delta W_{0}$ ) 
that is only a function of the type of sandstone undergoing acidization and independent of the entering acid conditions. For Phacoides sandstone the characteristic group given by Equation (15) was reported to be 0.159 I/gmole of acid (Lund and Fogler, 1976). However, a weighted average of the experiments carried out in Lund's thesis work (1974) shows that a somewhat better estimate of this group is a value of $0.14 \mathrm{l} / \mathrm{gmole}$ of acid. With the subscript $s$ referring to Phacoides sandstone, Equation (15) can be arranged to give

$$
\begin{aligned}
\left|\frac{A C \nu}{C_{0}}\right| & =\left|\frac{A c \nu}{C_{0}}\right|_{p} x \frac{\left|\frac{\phi_{0}}{1-\phi_{0}}\right|_{s}\left|\frac{1}{\Delta W_{o}}\right|_{s}}{\left|\frac{\phi_{0}}{1-\phi_{0}}\right|_{p}\left|\frac{1}{\Delta W_{0}}\right|_{p}} \\
& =0.14\left(\frac{\phi_{0}}{1-\phi_{0}}\right)_{s}\left(\frac{1-\phi_{0}}{\phi_{0}}\right)_{p} \frac{\left.\Delta W_{o}\right|_{p}}{\left.\Delta W_{o}\right|_{s}}
\end{aligned}
$$

The average porosity for the Phacoides sandstone was $11 \%$, and the percent of dissolvable minerals (lumped as feldspars) was 19.7 wt $\%$. The amount of dissolvable minerals is determined from an aluminum petrolog anal$y$ sis which is a special $x$-ray diffraction analysis with aluminum used as an internal standard. Since the results of this analysis are reported in terms of mass percent, it is preferable to express the concentration of dissolvable minerals in terms of mass $\Delta m$ rather than moles. This is easily achieved by multiplying $\Delta W_{0}$ by the average molecular weight of the dissolvable minerals $M$. The average molecular weight is the sum of the products of the mole fraction of mineral $i, Y_{i}$, and its molecular weight $M_{i}$. From these definitions, Equation (17) can now be written as

$$
\left|\frac{A c_{\nu}}{C_{0}}\right|_{s}=0.14\left(\frac{\phi_{0}}{1-\phi_{0}}\right)_{s}\left(\frac{1-\phi_{0}}{\phi_{0}}\right)_{p} \frac{\Delta m_{p}}{M_{p}} \cdot \frac{M_{s}}{\Delta m_{s}}
$$

In using the aluminum petrolog analysis to determine $\Delta m$, it is assumed that the proportionality constant (which is approximately 0.4) between the minerals accessible to reaction and all the dissolvable minerals is invariant for the different sandstones. For Phacoides sandstone, Table 1 gives the following average mineral composition in weight percent.

Owing to the very low reactivity of quartz relative to the other minerals in sandstone, it is considered virtually inert. The acid capacity number (and hence $\theta_{b}$ ) for various sandstones will now be calculated from previously published data by other investigators. The only information needed is the mineralogical analysis, the porosity of the sandstone, the entering hydrogen fluoride concentration, and in some cases the porosity-permeability relationship [that is, Equation (6) ].

We shall first consider a number of recent experiments by the authors on Berea sandstone. The data were reported in terms of the overall permeability ratio $K / k_{0}$ as a function of the dimensionless injection time $\theta$ (pore volumes injected). Based on the previous studies on Phacoides sandstone (Lund, 1974; Lund et al., 1976), together with the aluminum petrolog and porosity measurements, the values of the acid capacity and Damkohler numbers shall be determined for the Berea sandstone. These values will be substituted into Equation (8) which then will be combined with Equations (5), (6), and (7) to predict the overall permeability of the core as a function of pore volumes of acid injected. The results will then be compared with the experimental data.

Table 1. Aluminum Petrolog for Phacoides Sandstone (LUND AND FOGLER, 1976)

Wt. $\%$

Wt. \%

$\left.\begin{array}{lr}\text { Quartz } & 80.3 \% \\ \text { Plagioclase } & 5.9 \% \\ \text { K-feldspar } & 11.6 \% \\ \text { Kaolinite } & 0.8 \% \\ \text { Illite } & 1.4 \%\end{array}\right\}$ Inerts

Table 2. Aluminum Petrolog for Berea Sandstone (Chevron)

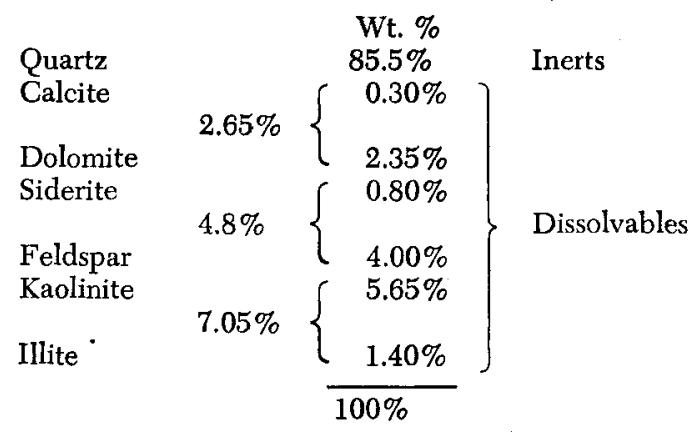

Wt. $\%$ $85.5 \%$

The Berea sandstone used in these experiments had the average composition given in Table 2 in terms of weight percent.

The porosity was found to be $19.2 \%$, and the value of $\beta$ in the porosity-permeability relationship is estimated from the Guin-Schechter correlation (1971) to be 5.0. This value was verified by an independent set of measurements. The dissolvable minerals are lumped into three groups: dolomite (2.65 wt. \%), feldspar (4.8 wt. $\%)$, and kaolinite $(7.05 \mathrm{wt}$. \%). The corresponding mole percent of the dissolvable material ( $38.1 \%$ Feldspar, $30.1 \%$ Kaolinite, $31.8 \%$ dolomite) gives the average molecular weight of the dissolvables in Berea sandstone as 320 . By comparison, the average molecular weight of Phacoides sandstone is 290 .

It is now possible to evaluate Equation (18) to determine the value of the group $\left[A c_{\nu} / C_{0}\right]_{B}$ for Berea sandstone from the aluminum petrolog analysis and the initial porosity:

$$
\begin{array}{r}
\left.\frac{A c \nu}{C_{0}}\right|_{B}=0.14 \times \frac{0.192}{0.808} \times \frac{0.89}{0.11} \times \frac{19.7}{290} \times \frac{320}{14.5} \\
=0.403 \mathrm{l} / \text { gmole }
\end{array}
$$

Before the acid capacity number can be determined from Equation (19), the mean stoichiometric coefficient $v$ for the Berea sandstone must first be calculated from the stoichiometric coefficients of the pure clays and minerals. The details of the calculations of the stoichiometric coefficients for the dissolution of kaolinite and of the feldspars in hydrogen fluoride as a function of temperature, hydrofluoric acid concentration, and hydrochloric acid concentration have been given by Hekim and Fogler (1976). The mean stoichiometric coefficient of the sandstone $\nu$ is

$$
\nu=\sum_{i=1}^{n} \nu_{i} Y_{i}=\nu_{D} Y_{D}+\nu_{K} Y_{K}+\nu_{F} Y_{F}
$$

where $\nu_{i}$ is the stoichiometric coefficient for species $i$ (clay or mineral). 
Table 3. Experimental Condrtions for Berea Sandstone Runs

\begin{tabular}{|c|c|c|c|c|c|c|c|c|}
\hline Run No. & $\begin{array}{l}\text { Flow rate, } \\
\text { min }\end{array}$ & $\begin{array}{c}\text { Concen- } \\
\text { tration, } \\
\text { mole } / 1 \mathrm{HCl}\end{array}$ & $\mathrm{HF}$ & $\begin{array}{l}\text { Length } \\
\text { core, cm }\end{array}$ & $\nu$ & $\begin{array}{l}\text { Space time } \\
\tau \text { min }\end{array}$ & $A c$ & $D a$ \\
\hline 583 & 20 & 2.92 & 2.5 & 5 & 16.93 & 0.23 & 0.0595 & 0.703 \\
\hline 585 & 20 & 2.92 & 2.50 & 7 & 16.93 & 0.32 & 0.0595 & 0.978 \\
\hline 591 & 5 & 1 & 1 & 2.5 & 15.55 & 0.46 & 0.0259 & 1.406 \\
\hline 596 & 5 & 1 & 1 & 5 & 15.55 & 0.92 & 0.0259 & 2.813 \\
\hline
\end{tabular}

For an acid mixture of $1 \mathrm{~N}$ hydrogen fluoride and $1 \mathrm{~N}$ hydrogen chloride, the stoichiometric coefficient for the pure minerals dolomite, feldspar, and kaolinite are 4.0 15.2, and 28.2, respectively (Hekim and Fogler, 1976). By evaluating Equation (20), the stoichiometric coefficient $\nu$ is found to be 15.55 gmole acid consumed/gmole of lumped mineral dissolved. For this value of $\nu$ and a 1 molar concentration of hydrogen fluoride, we find the acid capacity number to be 0.259 .

\section{Damkohler Number}

One now has only to estimate the Damkohler number before the model can be compared with the experimental results. The Damkohler number $D a$ is

$$
D a=\frac{k_{1} \Delta W_{0} L}{V}
$$

By dividing the Damkohler number by the space time $\tau$

$$
\tau=\frac{\phi_{0} L}{V}
$$

it can be put in a form which depends only upon the properties of the rock:

$$
\frac{D a}{\tau}=\frac{k_{1} \Delta W_{0}}{\phi_{0}}
$$

For Phacoides sandstone, Equation (23) was found to equal $8.0 \mathrm{~min}^{-1}$ (Lund and Fogler, 1976).

By the same procedure used above for the acid capacity numbers, the Damkohler number for a different sandstone $s$ can be estimated from the equation

$$
\begin{gathered}
\left|\frac{D a}{\tau}\right|_{s}=8 \cdot\left|\frac{\phi_{0}}{\Delta W_{o}}\right|_{p} \times\left|\frac{\Delta W_{o}}{\phi_{0}}\right|_{s} \\
\left|\frac{D a}{\tau}\right|=8 \cdot \frac{\phi_{0 p}}{\phi_{0 s}} \times \frac{\Delta m_{s}}{\Delta m_{p}} \times \frac{M_{p}}{M_{s}} \\
\frac{D a}{\tau}=8 \cdot \frac{0.11}{0.192} \times \frac{14.5}{19.7} \times \frac{290}{320}=3.06
\end{gathered}
$$

Once the entering acid concentration and flow rate are specified, the Damkohler and acid capacity numbers can be immediately determined from Equations (19) and (26). These values are substituted into Equation (9) which is then combined with Equations (5), (6), and $(7)$ to predict the overall permeability ratio of the core as a function of the dimensionless time of injection (that is, number of pore volumes). Table 3 gives the initial conditions for four different experimental runs for the acidization of Berea sandstone. The cores were preflushed with sodium chloride and distilled water before the acid was injected.

The experimental data for these runs, which were reported in terms of the overall permeability as functions of the dimensionless time $\theta$, are shown in Figures 1 through 4 along with the theoretical calculations described above. One can readily see that the agreement

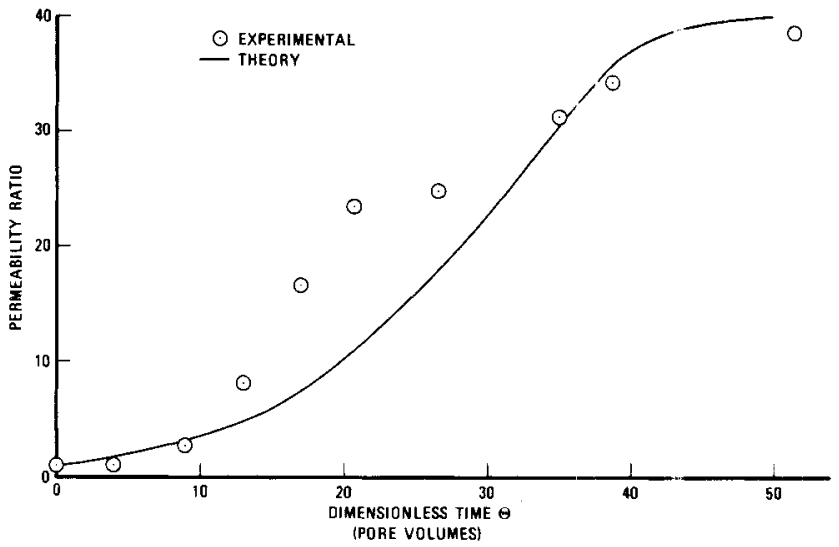

Fig. 1. Permeability vs. injection time. Berea sandstone Run 583.

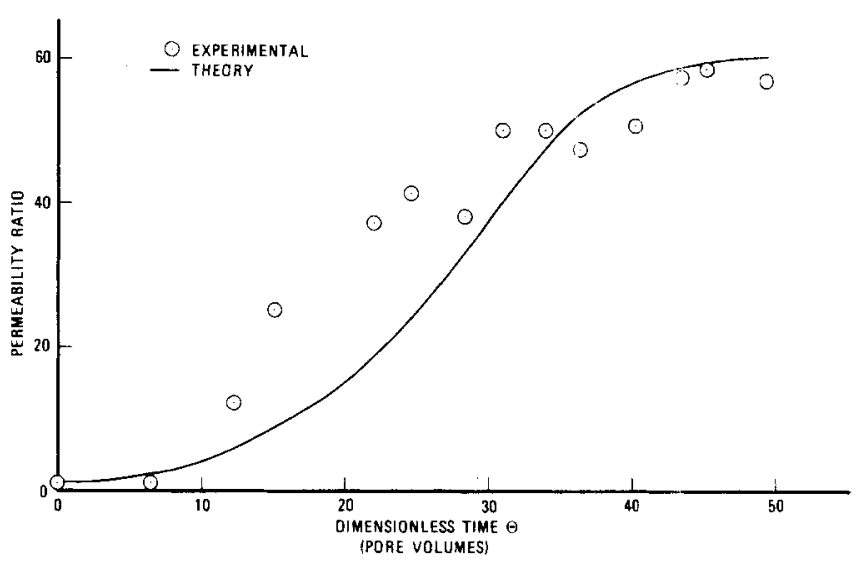

Fig. 2. Permeability vs. injection time. Berea sandstone Run 585.

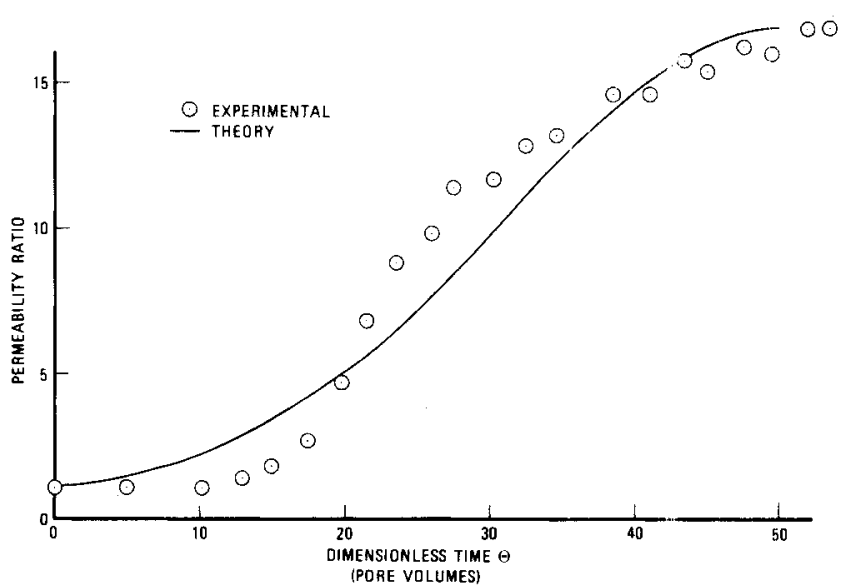

Fig. 3. Permeability vs, injection time. Berea sandstone Run 591.

between theory and experiment is remarkable.

Some of the first definitive laboratory experiments on acidization were carried out by Smith and Hendrickson (1965). Their mineralogical analysis is shown in Table 4. While the porosity of this sandstone was not reported in this paper, a later communication revealed it to be 


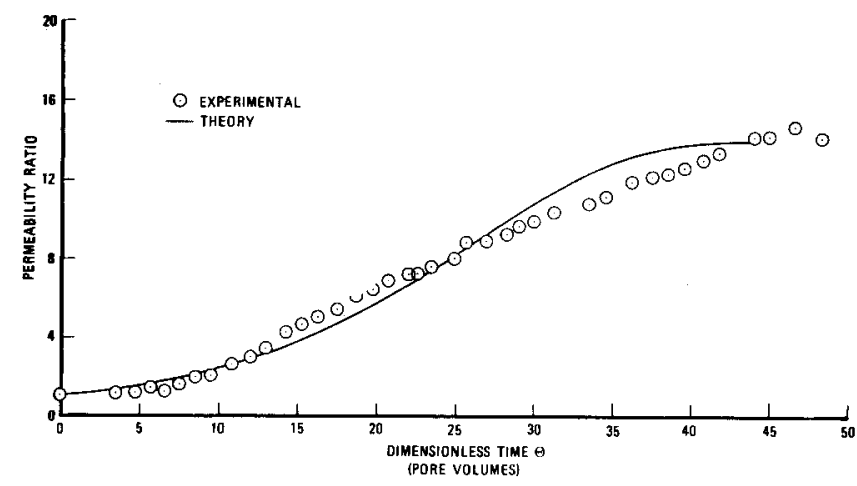

Fig. 4. Permeability vs. injection time. Berea sandstone Run 596.

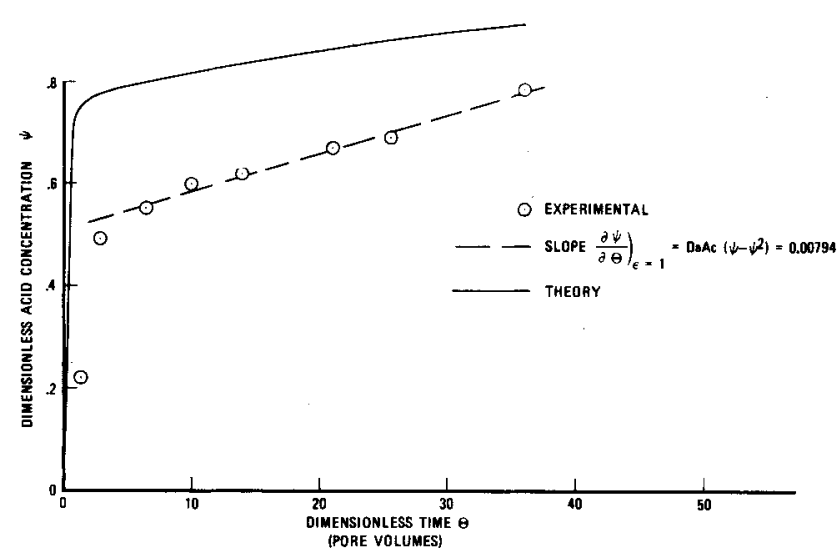

Fig. 5. Effluent acid concentration vs. injection time. Berea sandstone (from Figure 10, Williams and Whiteley-1971).

20\%. Evaluating Equation (18), we get

$$
\frac{A c \nu}{C_{0}}=0.38
$$

For an acid mixture of 2 wt. \% hydrogen fluoride and 13 wt. \% hydrogen chloride at $80^{\circ} \mathrm{F}$, the stoichiometric coefficients for potassium feldspar and kaolinite are 14.8 and 26.9, respectively (Hekim and Fogler, 1976). Consequently, the mean stoichiometric coefficient for the sandstone is 12.8. The entering hydrogen fluoride concentration was $2 \mathrm{wt}$. \% hydrogen fluoride (1 molar) which corresponds to an acid capacity of 0.0296 .

Since the experiments of Smith and Hendrickson were carried out at constant pressure (variable flow rate) and the model described above is for a constant flow system, only a rough comparison between the two can be made. We can only choose the permeability breakthrough time as a basis for comparison. Smith and Hendrickson have reported their data in figures showing the permeability ratio as a function of the number of pore volumes injected. These figures permit the estimation of $\theta_{b}$ (or pore volumes) by a method consistent with that used in a previous paper by the authors for Phacoides sandstone from similar data (Lund et al., 1976). Based on the curve for Berea sandstone in Figure 13 and the curves for small pressure drops in Figure 11 in the Smith and Hendrickson paper, $\theta_{b}$ is estimated to lie between 40 and 50. From Equation (12), the number of pore volumes needed to be injected to reach breakthrough is calculated as

$$
\theta_{b}=1+1 / A c=35
$$

Table 4. Aluminum Petrolog for Berea Sandstone (Smith ANd Hendrickson, 1965)

Wt. \%

\begin{tabular}{|c|c|c|c|}
\hline \multirow[t]{2}{*}{$\begin{array}{l}\text { Quartz } \\
\text { Feldspar } \\
\text { Dolomite } \\
\text { Clay }\end{array}$} & $\begin{array}{r}85.3 \% \\
5.0 \% \\
4.0 \% \\
5.7 \% \\
\end{array}$ & Dissolvables & $85.3 \%$ \\
\hline & $100 \%$ & & $100 \%$ \\
\hline
\end{tabular}

Wt. \%

Table 5. Aluminum Petrolog for Berea Sandstone (Williams aNd Whiteley, 1971)

Wt. \%

Wt. \%

$\left.\begin{array}{lr}\text { Quartz } & 15.4 \% \\
\text { Feldspar } & 1.5 \% \\
\text { Dolomite } & 0.2 \% \\
\text { Clays } & 2.9 \%\end{array}\right\} \quad$\begin{tabular}{l} 
Inerts \\
\cline { 2 - 3 }
\end{tabular}

Even with the different conditions between the experiment and the model, the number of pore volumes to reach permeability breakthrough calculated from the model is in reasonable agreement with the experimental values obtained by Smith and Hendrickson.

Other experiments were carried out more recently by Williams and Whiteley (1971) on a Berea sandstone which had very little dissolvable material. Since extension of the model to high temperatures (about $100^{\circ} \mathrm{C}$ ) is not certain at this time, owing to a lack of data of the relative rate of dissolution of clays and minerals at high temperatures, only Williams and Whiteley's experiments carried out around $25^{\circ} \mathrm{C}$ will be analyzed. Table 5 gives mineralogical analysis of this sandstone.

The porosity was given as $19.8 \%$. The group $\left|A c v / C_{0}\right|$ and $\nu$ corresponding to this sandstone were calculated by the method described above and found to be 1.57 l/gmole and 19.8 gmole acid consumed/gmole rock dissolved, respectively. For the entering concentration of 1.6 molar hydrogen fluoride, the corresponding acid capacity number is 0.127 . However, because the data of Williams and Whiteley are reported in terms of effluent hydrogen fluoride acid concentration as a function of pore volumes injected, our analysis must be carried further before a direct comparison between the model and their experiments can be made. While there is some controversy about the use of a fluoride specific ion electrode to measure the exact hydrogen fluoride concentration directly, the general trends of the variation of hydrogen fluoride concentration with time should be valid. The $24^{\circ} \mathrm{C}$ data from Figure 10 of Williams and Whiteley are replotted in Figure 5. To predict the corresponding effluent hydrogen fluoride concentration as a function of $\theta$ from the model, Equation (8) is simply evaluated at $\epsilon=1$ :

$\Psi=$ 1

$1+\exp \left[D a A c\left|\left(1+\frac{1}{A c}\right)-\theta\right|\right]-\exp [D a A c(1-\theta)]$

For the sandstone described in Table 5

$$
\frac{D a}{\tau}=0.79
$$




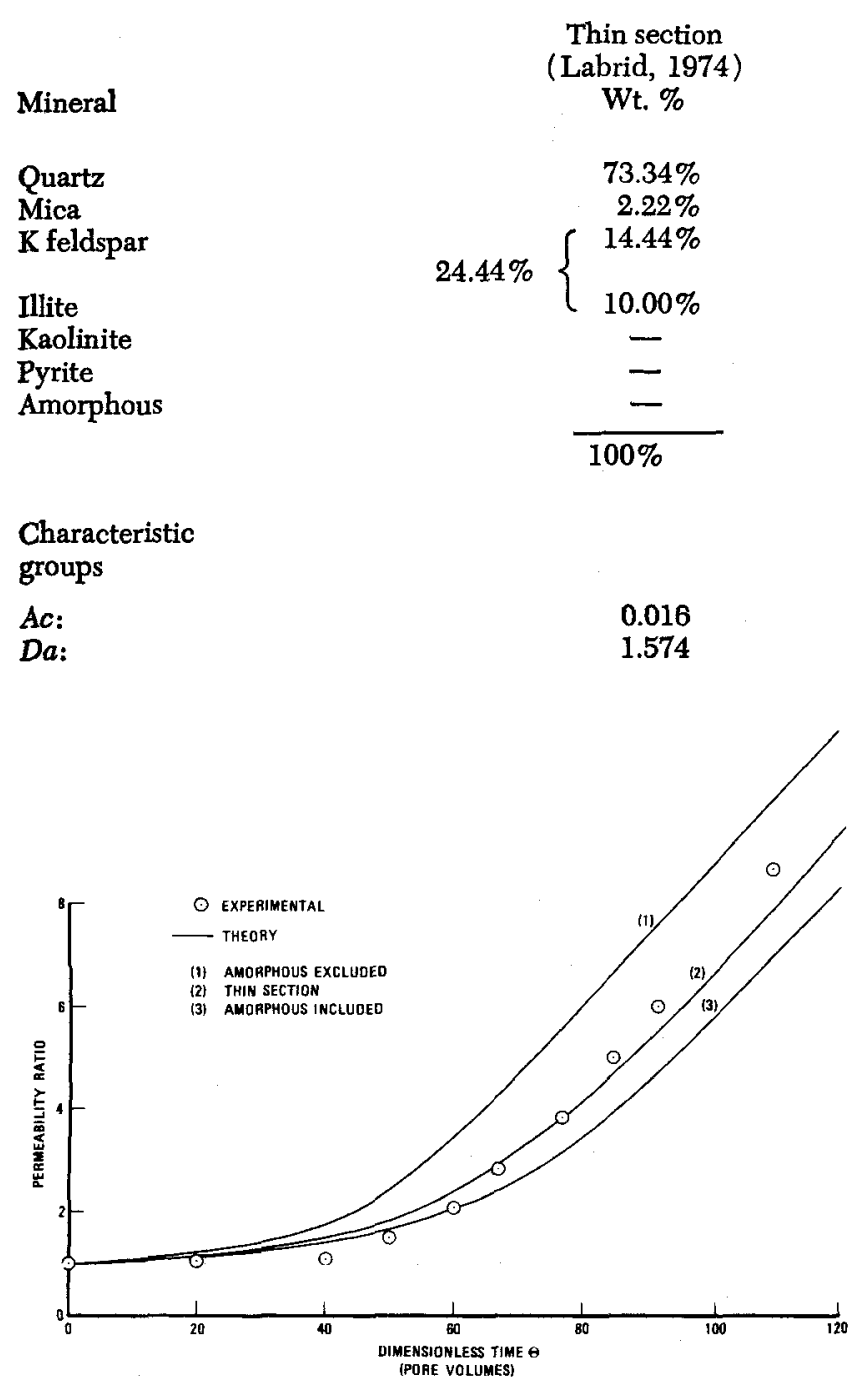

Fig. 6. Permeability vs. injection time. Fontainebleau illitic sandstone (Labrid 1975-Figure 13).

The space time for the $24^{\circ} \mathrm{C}$ run of Williams and Whiteley in which the core length was $9.51 \mathrm{~cm}$ and the flow rate $0.44 \mathrm{~cm}^{3} / \mathrm{s}(V=5.21 \mathrm{~cm} / \mathrm{min})$ is $0.361 \mathrm{~min}$, and the corresponding Damkohler number is 0.285 . This value of $D a$ and the corresponding value of $A c$ were substituted into Equation (27) to yield the theoretical curve for the dimensionless hydrogen fluoride concentration as a function of $\theta$ shown in Figure 5. One observes that the slopes of the calculated and experimental curves are nearly identical. As previously mentioned, the fluoride electrode may not give an absolute measurement of the hydrogen fluoride concentration owing to the presence of the aluminum and silicon fluoride complexes as well as mixing effects with the water initially present in the core. Consequently, a better comparison between theory and experiment would be to determine the product DaAc from the slope of the curve giving the experimental values of $\Psi$ as a function of $\theta$ and then to compare it with the value calculated from the model. The time rate of change of the effluent hydrogen fluoride concentration (in dimensionless form) can be found by differentiation and subsequent rearrangement of Equation (27):

$$
\left(\frac{\partial \Psi}{\partial \theta}\right)_{\epsilon=1}=\operatorname{DaAc}\left(\Psi^{2}-\Psi\right)
$$

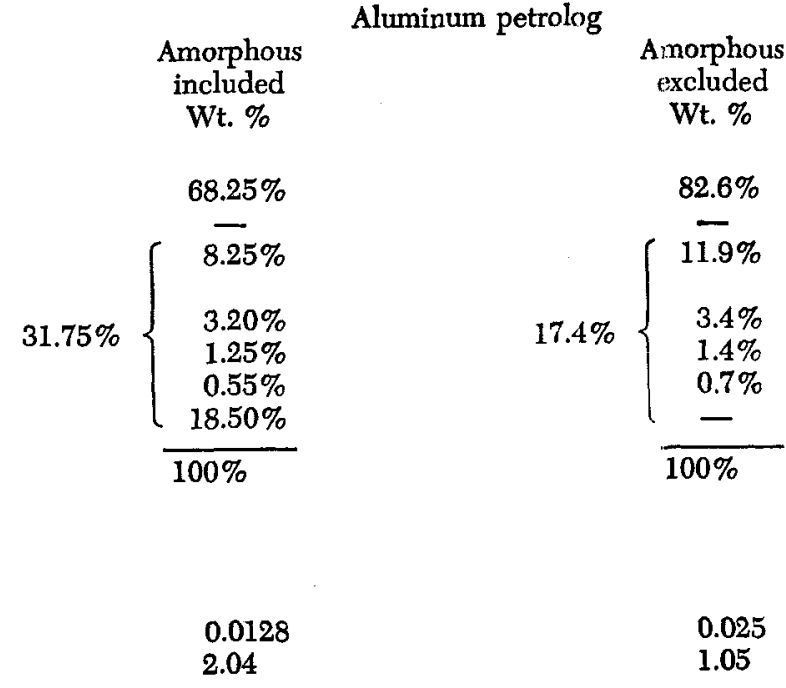

The left-hand side of Equation (33) is just the slope of the curves given in Figure 5. After the initial transient dies out $(\theta>2)$, the value of the slope of $\Psi$ vs. $\theta$, $\partial \Psi / \partial \theta$, is equal to 0.0074 for the data $24^{\circ} \mathrm{C}$. The corresponding values of the product $|D a A c|$ lie between

for

$$
0.032<D a A c<0.042
$$

$$
0.55<\Psi<0.75
$$

Taking the average value at $\Psi=0.65$, we get

$$
\left.D a A c\right|_{\exp }=0.035
$$

Using the values of $D a$ and $A c$ calculated from the model for this sandstone, we get

$$
\left.D a A c\right|_{\text {calc }}=(0.285)(0.127)=0.036
$$

There are no adjustable parameters in these calculations, and one readily observes that the experimental and predicted values agree very well.

Experiments similar to those described above have been carried out on a French illitic sandstone by Labrid (1975) at the Institut Francais du Petrole. The porosity of this sandstone was found to be $22 \%$, while the mineral composition was determined by two different methods: thin section analysis (Labrid, 1974, 1975) and an aluminum petrolog analysis. The aluminum petrolog analysis, which was carried out on these samples at Chevron Oil Field Research Company, showed a large amount of amorphous material. At this time it is uncertain as to whether the amorphous material should be included as dissolvable material. Consequently, we shall carry out calculations which both include and exclude the amorphous material in the acid capacity and Damkohler numbers. The mineral composition is given in Table 6 .

The permeability-porosity relationship given in Figure 15 of Labrid's paper can be quite well approximated by

$$
k / k_{0}=A_{i} e^{B_{i}\left(\phi-\phi_{0}\right)}
$$

with $A_{1}=1$ and $B_{1}=5.9$ for $\phi / \phi_{0}<1.3$

$$
\begin{aligned}
& A_{2}=0.5 \text { and } B_{2}=16.3 \text { for } 1.3<\phi / \phi_{0}<1.4 \\
& A_{3}=1.4 \text { and } B_{3}=31.6 \text { for } \phi / \phi_{0}>1.4
\end{aligned}
$$

To obtain $\beta$ [used in Equation (6)] one multiplies $B_{i}$ by $\Delta \phi_{m}$. The value of $\Delta \phi_{m}$ for the illitic sandstone was taken as 0.15 .

A mixture of 1 molar hydrogen fluoride/1.11 molar 
hydrogen chloride was injected into a core $1 \mathrm{~cm}$ in length at a rate of $2.4 \mathrm{~cm}^{3} / \mathrm{min}$, and the overall permeability was recorded as a function of time and acia vorume injected. The acid capacity and Damkohler numbers corresponding to these conditions are given in Table 6 for the three interpretations of the mineral analysis. These values were used in obtaining the calculated values of the overall permeability as a function of time in an identical manner to that discussed above for Berea sandstone. The response to the acidization of the illitic sandstone predicted by the model is shown in Figure 6 along with the experimental data presented in Figure 13 of Labrid (1975). As in the previous cases, the agreement is excellent.

As with any model, application of this model should not be carried to extremes, but it should be applicable to various sandstones with properties similar to the ones described above. However, one still should carry out experimental measurements whenever possible to determine the acid capacity and Damkohler numbers along with the permeability-porosity relationship. For sandstones with widely different properties (for example, degree of consolidation, pore size distribution, large carbonate or clay contents, etc.) one would have to make the necessary modifications to account for such things as channeling, mass transfer resistance, a greater percentage of dissolvable material than inerts, and excessive damage that may occur during acidization.

\section{SUMMARY}

It has been shown that the model can be extended to describe the matrix acidization of a number of different sandstones. This is achieved through prediction of the acid capacity and Damkohler numbers for these sandstones solely from mineralogical analysis and porosity measurements on the sandstone. Experiments carried out by other investigators as well as those conducted by the authors were found to agree very well with the theory. The extension of the model to different sandstones will be of use in the design of acid stimulation of oil and gas wells in the field.

\section{NOTATION}

$A c=$ acid capacity number dimensionless $=\phi_{0} C_{o} /$ $\left[\nu\left(1-\phi_{0}\right) \Delta W_{o}\right]$

$C=$ concentration of hydrogen fluoride, gmole/l

$D a=$ Damkohler number $=k_{1} L \Delta W_{0} / V$

$k=$ local permeability, darcies

$k_{1}=$ specific reaction rate

$K=$ overall permeability of core, darcies

$L=$ length of core, $\mathrm{cm}$

$M_{F}=$ average molecular weight of the feldspars

$M_{j}=$ molecular weight of mineral species $j$

$t=$ time, min

$t_{b}=$ breakthrough time, $\mathrm{min}$

$V=$ superficial velocity, $\mathrm{cm} / \mathrm{min}$

$Y_{i}=$ mole fraction of species $i$

$z=$ axial distance in the core, $\mathrm{cm}$

\section{Greek Letters}

$\beta=$ characteristic constant for acidization

$\Delta_{m}=$ mass concentration of lumped minerals accessible to reaction, gmole $/ \mathrm{cm}^{3}$ of solid

$\Delta W=$ molar concentration of lumped minerals in solid accessible to reaction, gmoles $/ \mathrm{cm}^{3}$ solid

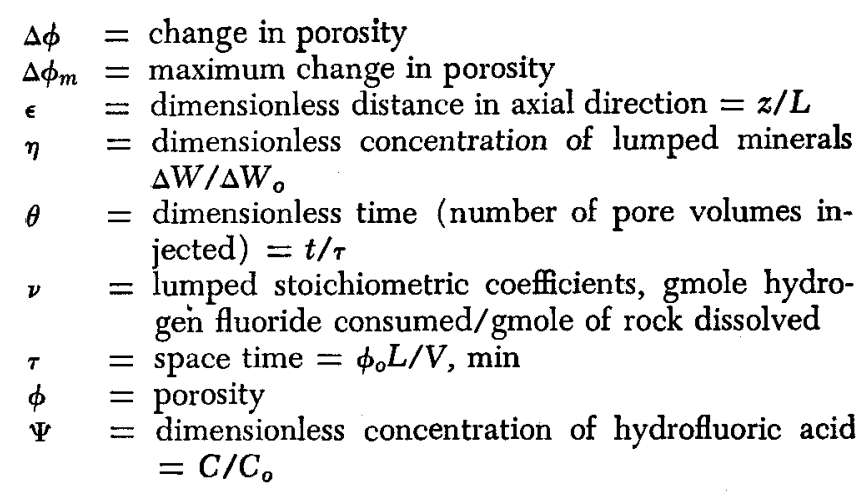

Subscripts

$o \quad=$ entering conditions of the acid (for example, $C_{o}$ ) or initial conditions of the rock (for example, $\left.\phi_{o}, \Delta W_{o}\right)$

$i=$ indexes

$K=$ Kaolinite

$D=$ Dolomite

$F \quad=$ Feldspar

\section{LITERATURE CITED}

Fogler, H. S., K. Lund, and C. C. McCune, "Acidization III. The Kinetics of the Dissolution of Sodium and Potassium Feldspar in Hydrochloric-Hydrofluoric Acid Mixtures," Chem. Eng. Sci., 30, 1325 (1975).

Guin, J. A., and R. S. Schechter, "Matrix Acidizing with Highly Reactive Acids," Soc. Petrol. Eng. J., 11, 390 (1971).

Hekim, Y., and H. S. Fogler: "Acidization VII. On the Stoichiometric and Equilibrium Relationships for the Dissolution of Two Alumino-Silicates in Mud Acid," accepted for publication in Chem. Eng. Sci. (1976).

Labrid, J. C., "Thermodynamic and Kinetic Aspects of Argillaceous Sandstone Acidizing," Soc. Petrol. Eng. J., 15, No. $2,117(1975)$.

, Private communication, Paris, France (Sept., 1974).

Lund, K., Ph.D. thesis, "On the Acidization of Sandstone," Univ. Mich., Ann Arbor (1974).

- H. S. Fogler, and C. C. McCune, "Acidization I. The Dissolution of Dolomite in Hydrochloric Acid," Chem. Eng. Sci., 28, 691 (1973).

, and J. W. Ault, "Acidization II. The Disolution of Calcite in Hydrochloric Acid," ibid., 30, 825 ( 1975).

Technique "Acidization IV. Experimental Correlations and Techniques for the Acidization of Sandstone Cores." ibid. 31, 373 (1976).

Lund, K., and H. S. Fogler, "Acidization V. The Prediction of the Movement of Acid and Permeability Fronts in Sandstone," ibid., 31, 381 (1976).

McCune, C. C., and H. S. Fogler, "An Experimental Technique for Obtaining Permeability-Porosity Relationships in Acidization," paper No. 52e, 74th National AIChE Meeting, New Orleans, La. (1973).

McCune, C. C., J. R. Cunningham, H. S. Fogler, K. Lund, and J. W. Ault, "A New Model of the Physical and Chemical Changes in Sandstone During Acidizing," Soc. Petrol. Eng. $J ., 15,361$ (1975).

Smith, C. F., and A. R. Hendrickson, "Hydrolluoric Acid Stimulation of Sandstone Reservoirs," J. Petrol. Technol., 17, No. 2,215 (1965).

Williams, B. B., and M. E. Whiteley: "Hydrofluoric Acid Reaction with a Porous Sandstone," Soc. Petrol. Eng. J., 11, No. 3, 306 (1971).

Manuscript received July 14, 1975; revision received March 5 and accepted April 30, 1976 . 